\title{
Correlations of Autopsy and Postmortem CT in Fatal Ballistic Injuries
}

\author{
Pierre Gach ${ }^{1}$, Lucile Tuchtan ${ }^{2,3}$, Julien Mancini ${ }^{4}{ }^{\circledR}$, Clémence Delteil $^{2,3}$, Pierre Massiani ${ }^{2}$, Christophe Bartoli $^{2,3}$, \\ Marie-Dominique Piercecchi ${ }^{2,3}$ and Guillaume Gorincour $5, *$ (i) \\ 1 Radiology Department, Hôpital de la Timone (AP-HM), 13385 Marseille, France; pierre.gach@ap-hm.fr \\ or pierre.gach@gmail.com \\ 2 Forensic Department, Hôpital de la Timone (AP-HM), 13385 Marseille, France; lucile.tuchtan@ap-hm.fr (L.T.); \\ clemence.delteil@ap-hm.fr (C.D.); pierre.massiani@ap-hm.fr (P.M.); christophe.bartoli@ap-hm.fr (C.B.); \\ marie-dominique.piercecchi@ap-hm.fr (M.-D.P.) \\ 3 CNRS, EFS, ADES, Aix Marseille Université, 13385 Marseille, France \\ 4 Department of Biostatistics, Information and Communication Technologies (BioSTIC), Hôpital de la Timone, \\ APHM, INSERM, IRD, SESSTIM, Aix Marseille Université, 13385 Marseille, France; julien.mancini@ap-hm.fr \\ 5 Clinique Bouchard-Elsan, 13008 Marseille, France \\ * Correspondence: guillaume.gorincour@gmail.com
}

check for

updates

Citation: Gach, P.; Tuchtan, L.; Mancini, J.; Delteil, C.; Massiani, P.; Bartoli, C.; Piercecchi, M.-D.; Gorincour, G. Correlations of Autopsy and Postmortem CT in Fatal Ballistic Injuries. Forensic Sci. 2022, 2, 190-200. https://doi.org/10.3390/ forensicsci2010015

Academic Editors: Dominic Gascho and Sören Kottner

Received: 15 December 2021

Accepted: 23 February 2022

Published: 26 February 2022

Publisher's Note: MDPI stays neutral with regard to jurisdictional claims in published maps and institutional affiliations.

Copyright: (C) 2022 by the authors. Licensee MDPI, Basel, Switzerland. This article is an open access article distributed under the terms and conditions of the Creative Commons Attribution (CC BY) license (https:// creativecommons.org/licenses/by/ $4.0 /)$.

\begin{abstract}
Purpose: To study the respective contributions and correlations of autopsy and PMCT in fatal ballistic injuries. Methods: A single-center retrospective descriptive study was carried out over a 10-years period (2008-2017) that included cases of fatal ballistic injuries that had undergone unenhanced PMCT followed by autopsy. In addition to demographics, the main data collected independently at autopsy and PMCT were the number of injuries, their trajectory, distances from the sole of the feet of the entry and exit wounds, projectile caliber and gunshot residue, detailed examination of the injuries, and detection of effusions. Results: Initially, 225 cases were included, of which 158 complete records were analyzed. The mean age of the victims was 41.5 years, and $93 \%$ were male. PMCT and autopsy findings were concordant concerning the number of injuries, their trajectory, and distance of the entry and exit wounds from the sole of the feet. Findings were not concordant regarding gunshot residues on the skin (autopsy more efficient) or detection of effusions (PMCT more efficient). The limitations of PMCT were the positioning of the limbs outside the field of acquisition and the impossibility of reliably determining the caliber of the projectiles. Some discrepancies were related to occasionally missing autopsy data, particularly the distance from the sole of the feet or measurements of the volume of effusion. Conclusions: This study provides more detailed knowledge of the accordance of autopsy and PMCT in analyzing fatal ballistic injuries.
\end{abstract}

Keywords: ballistics; postmortem computed tomography; autopsy; correlation; forensic pathology

\section{Introduction}

Medical imaging, and especially computed tomography (CT), is a tool whose contribution is now recognized in forensic medicine, notably in the analysis of ballistic injuries [1-6]. Unlike autopsy, which is usually performed once, save from some exceptions, postmortem CT (PMCT) images can be reviewed, shared, or used as a source of demonstrative 3D images in a court setting [7]. Few large series evaluating the contribution of PMCT to the analysis of death by firearms have been published [8-11]. Nevertheless, this tool is increasingly accessible worldwide, whether in regard to cost, speed of acquisition, or the number of devices. In parallel, the number of deaths by shooting increases every year [12]. The possibility of using PMCT in the context of terrorism has also been suggested [13]. Our aim was to study the respective contributions and correlations between autopsy and PMCT findings in fatal ballistic injuries. 


\section{Materials and Methods}

We carried out a single-center retrospective descriptive study from September 2008 to September 2017. PMCT records were extracted from the radiological information and the digital archiving systems of our institution, and we consulted the autopsy reports of the forensic medicine department. Primarily, we included all cases of fatal ballistic injuries that had undergone unenhanced PMCT followed by autopsy. Secondarily, we excluded cases where charring and/or putrefaction were too advanced for PMCT examination to be informative: those where the autopsy report was not yet available; those which, before PMCT and autopsy, had undergone surgery that could modify the characteristics of the injury; and those that had received more than 7 ballistic injuries (more than 7 trajectories or more than 7 projectiles at autopsy).

\subsection{Autopsy Data}

We collected the following epidemiological data, based on the autopsy reports: gender, date of birth, date of death (or date of an autopsy if the date of death was uncertain), and whether the death was due to homicide or suicide. The caliber of the projectile was recorded from autopsy and, where applicable, from the ballistic expert report. The range of discharge of a firearm (contact and close range) was recorded where applicable.

\subsection{Imaging Data}

The CT devices used were a Siemens Somatom Definition (Siemens Healthineers headquarters: Erlangen, Germany) and a General Electrics Optima CT 660 (GE Healthcare headquarters: Chicago, IL, USA).

The acquisition protocol was as follows:

- $\quad$ anteroposterior scout view with the body in a supine position, arms resting along the body.

- unenhanced cervicocranial acquisition, in contiguous 1-mm sections, processed to obtain reconstructions of the skeleton and brain parenchyma in contiguous 3-mm axial sections.

- unenhanced acquisition, in 1-mm sections, from the cervical region to the soles of the feet, processed to obtain reconstructions of the skeleton, mediastinum, and lung parenchyma in contiguous 5-mm axial sections.

- multiplanar reconstructions (MPR) and maximum intensity projection (MIP) reconstructions.

The technical parameters were as follows:

- Tube voltage: $120 \mathrm{kVp}$.

- Tube current: $1000 \mathrm{mAs}$ for the cervicocranial acquisition and $300 \mathrm{mAs}$ for the wholebody acquisition.

- $\quad$ Soft and hard kernels for both acquisitions.

\subsection{Complementary Ballistic Analysis}

The following data were collected blindly from the PMCT data and the autopsy report, using the same methodology: number of projectiles, number of injuries, trajectory of the projectile within the body, distance from the sole of the feet of the entry or exit wounds, and gunshot residue on the body and clothing if present.

On PMCT, the search for the projectile began with the scout view analysis and was refined by reading all multiplanar reconstructions. If separated, the core of a projectile and its jacket were counted as a single projectile.

At both autopsy and CT, we described the trajectories in the three spatial planes, according to the method used by forensic pathologists: the trajectory could be upward or downward, towards the left or the right, in an anterior or posterior direction, according to a reference plane showing an individual in the anatomical reference position: standing erect, with the arms at the sides of the body and palms facing forward. 
If one, two, or all three trajectory wounds were not recorded in the autopsy report, we considered that the trajectory was not described by autopsy.

We used various landmarks and semiological features to identify the trajectories and surface wounds $[9,10]$.

On CT, the distance from the wound orifices to the soles of the feet was measured by selecting the sagittal view of the whole-body scan and then using the MIP function to obtain an image composed of the skeleton and a summary view of the surrounding soft tissue. We then used the axial plane proposed by the software to place a landmark on the surface wound and measured the distance between this point and the sole of the foot on the sagittal MIP view. At autopsy, these distances were directly measured.

\subsection{Injury Analysis}

Injuries were described in each body segment, from the cranium to the sole of the feet, by examining various vascular structures (thoracic and abdominal aorta, supra-aortic arterial trunks, mesenteric vessels, inferior vena cava), as well as each organ, each bone segment and search for effusion adjacent to solid intra-abdominal organs. We sought and quantified hemothorax and hemoperitoneum and described pneumoperitoneum. Effusion volume was measured using the appropriate module of the reconstruction software (manual measure, image by image, on axial views).

Injuries were detailed following the same descriptive protocol at autopsy and PMCT.

Brain lesions identified were parenchymal lesions, subarachnoid hemorrhage, subdural hematoma, extradural hematoma, and intraventricular hemorrhage.

Cervical injuries identified were injuries of the supra-aortic arterial trunks and laryngeal cartilage injury.

Thoracic injuries identified were injuries of the heart and the right or left lung, hemopericardium, hemothorax, and left or right pneumothorax.

Each solid intra-abdominal organ was examined, looking for perforation of the stomach, small intestine, and colon, and injury of the thoracic and abdominal aorta, bladder, root of the mesentery, and inferior vena cava. Effusion adjacent to each intra-abdominal organ was recorded if present [14].

The following bone injuries were detailed: fractures of the cranial vault, facial bones, base of the skull; cervical, thoracic, lumbar, and sacral spine; thoracic and pelvis girdles; ribs; upper and lower limbs.

Autopsies were performed by the forensic pathologists of our institution $(>15$ different people), with various experience in ballistic deaths. Most of them did not benefit from the PMCT data at the time of the autopsy. Forensic pathologists worked in pairs on each autopsy.

CT data were analyzed by a resident in radiology with 2.5 years experience in PMCT, blinded from the autopsy report.

\subsection{Statistical Analysis}

Categorical variables are presented as numbers (\%). Quantitative variables are presented as mean \pm standard deviation. Agreement between CT and autopsy was evaluated using Cohen's kappa coefficient $(\kappa)$ for binary variables and the intraclass correlation coefficient (ICC) for quantitative variables [15]. All analyses were carried out using IBM SPSS Statistics 20.0 software (IBM Inc., New York, NY, USA). For all two-tailed tests, a $p$-value less than 0.05 was considered statistically significant.

\section{Results}

We initially recruited 225 cases. Secondly, 10 cases were excluded because of excessive charring, 1 for advanced putrefaction, 4 because PMCT images could not be accessed (PACS storage errors), 2 because the autopsy report was missing, 5 because surgery had been performed before CT scan and autopsy, and 45 because there were more than 7 injuries. Finally, 158 cases were analyzed. The demographic characteristics are in Table 1. 
Table 1. Study demographics. Sex ratio, homicide and suicide ratio, and mean age of the victims.

\begin{tabular}{cc}
\hline Characteristics & Value \\
\hline Men, No. (\%) & $147(93)$ \\
Homicide, No. (\%) & $113(71.5)$ \\
Suicide, No. (\%) & $45(28.5)$ \\
\hline \multicolumn{2}{c}{ Mean Age, year, Mean \pm SD } \\
\hline Homicide & $34.2 \pm 13.3$ \\
Suicide & $59.8 \pm 14.6$ \\
All & $41.5 \pm 17.9$ \\
\hline
\end{tabular}

Wounds corresponded to cutaneous defects associated with subcutaneous emphysematous air. The blood pathway appeared as linear hyperattenuation within muscle masses or the brain parenchyma. In solid organs and the lungs, the pathway was identified by the presence of additional air.

When a projectile fractured a bone, some wound pathways could be reconstructed from the fragments produced. Some pathways could also be deduced from a beveling orifice in the cranial vault as the cone widens in the projectile's trajectory.

Autopsy reports revealed varied specific calibers: 39 cases involved a 12 gauge, 31 cases involved a $9 \mathrm{~mm}, 14$ cases involved a $7.62 \mathrm{~mm}, 9$ cases involved a 0.22 Long Rifle, 3 cases involved a $0.45,3$ cases involved a 0.38 special, and 1 case involved a 0.357 Magnum. Some autopsy reports did not specify the caliber involved: the caliber was designated as "small", "medium", "large", or "unspecified".

PMCT was concordant with an autopsy for the number of projectiles (ICC $=0.660$ ), number of injuries (ICC $=0.700)$, their trajectory $(\kappa \geq 0.925)$, and the distance from the soles of the feet to the entry and exit wounds (ICC $\geq 0.993$ ).

PMCT and autopsy were also concordant regarding brain injury (ICC $=0.893)$, mediastinal injury (ICC $=0.914$ ), lung parenchyma injury (right lung $\mathrm{K}=0.958$, left lung 0.973), intra-abdominal solid organ injury (ICC $=0.969)$, thoracic aorta injury $(\kappa=0.886)$, abdominal aorta injury $(\kappa=0.794)$, skull fractures $(\mathrm{ICC}=0.996)$, and lower limb bone fractures (left lower limb ICC $=0.662$, right lower limb ICC $=0.927$ ).

Concordance between PMCT and autopsy was more variable regarding spinal fractures (cervical spine $K=0.589$, thoracic spine $K=0.844$, lumbar spine $K=0.766$ ), sacrum $(\kappa=0.589)$, scapular fractures (right $K=0.610$, left $K=0.445$ ), fractures of the ischiopubic ramus $(\kappa=0.664)$, hemopericardium $(\kappa=0.762)$, injury of the supra-aortic arterial trunks $(\kappa=0.613)$, hand fractures (right $\kappa=0.738$ and left $\kappa=0.744)$, perforation of the small intestine $(\kappa=0.609)$, or colon $(\kappa=0.633)$.

PMCT and autopsy were not concordant regarding gunshot residue on the skin ( $\kappa=0.278$ ) where the CT scan was inferior, and pneumothorax (right $\kappa=0.306$, left $\mathrm{K}=0.301)$ and detection of hemoperitoneum related to solid intra-abdominal injury $(\mathrm{ICC}=0.293)$ where the autopsy was inferior. The autopsy was also inferior for detecting inferior vena cava injury $(\kappa=-0.017)$.

Table 2 reports all lesional items and the number of times they were identified on the autopsy and CT scan data. The ICC and kappa were derived from Table 2.

Table 2. Lesional items. The left column lists all the lesional items identified on CT scan data and autopsy reports. The middle and right columns list the number of times these items were identified on CT scan data and autopsy reports.

\begin{tabular}{ccc}
\hline Anatomic Items & CT & Autopsy \\
\hline Parenchymal brain lesion & 87 & 87 \\
Subarachnoid hemorrhage & 77 & 67 \\
\hline
\end{tabular}


Table 2. Cont.

\begin{tabular}{|c|c|c|}
\hline Anatomic Items & $\mathrm{CT}$ & Autopsy \\
\hline Subdural hematoma & 8 & 7 \\
\hline Epidural hemorrhage & 0 & 1 \\
\hline Intra-ventricular hemorrhage & 62 & 42 \\
\hline Brain lesion & 234 & 204 \\
\hline Cardiac lesion & 34 & 35 \\
\hline Hemopericardium & 24 & 26 \\
\hline Supra-aortic trunks lesion & 19 & 9 \\
\hline Laryngeal cartilages lesion & 13 & 12 \\
\hline Right pneumothorax & 58 & 15 \\
\hline Right hemothorax & 61 & 53 \\
\hline Right lung lesion & 57 & 54 \\
\hline Left pneumothorax & 64 & 17 \\
\hline Left hemothorax & 68 & 58 \\
\hline Left lung lesion & 63 & 61 \\
\hline Pneumothorax & 122 & 32 \\
\hline Hemothorax & 129 & 111 \\
\hline Thoracic aorta lesion & 19 & 21 \\
\hline Abdominal aorta lesion & 6 & 4 \\
\hline Liver lesion & 34 & 36 \\
\hline Spleen lesion & 17 & 15 \\
\hline Pancreas lesion & 14 & 16 \\
\hline Right kidney lesion & 6 & 7 \\
\hline Left kidney lesion & 5 & 5 \\
\hline Solid intra-abdominal organ lesion & 76 & 79 \\
\hline Peri-liver effusion & 36 & 1 \\
\hline Peri-spleen effusion & 29 & 3 \\
\hline Peri-pancreatic effusion & 8 & 6 \\
\hline Peri-right kidney effusion & 5 & 5 \\
\hline Peri-left kidney effusion & 6 & 0 \\
\hline Effusion close to solid intra-abdominal organs & 84 & 15 \\
\hline Stomach perforation & 24 & 22 \\
\hline Small bowel perforation & 22 & 12 \\
\hline Large bowel perforation & 22 & 11 \\
\hline Bladder perforation & 2 & 2 \\
\hline Mesenteric lesion & 10 & 12 \\
\hline Inferior cava vein lesion & 4 & 2 \\
\hline Cranial vault fracture & 85 & 85 \\
\hline Paranasal sinuses fracture & 67 & 66 \\
\hline Basal skull fracture & 68 & 69 \\
\hline Skull fracture & 220 & 220 \\
\hline Cervical spine fracture & 24 & 11 \\
\hline Thoracic spine fracture & 36 & 28 \\
\hline Lumbar spine fracture & 13 & 10 \\
\hline Right clavicle fracture & 5 & 5 \\
\hline Right scapula fracture & 12 & 7 \\
\hline Left clavicle fracture & 9 & 5 \\
\hline Left scapula fracture & 10 & 3 \\
\hline Thoracic girdle fracture (scapula + clavicle) & 36 & 20 \\
\hline Sternum fracture & 13 & 6 \\
\hline Right rib fracture & 57 & 52 \\
\hline Left rib fracture & 64 & 61 \\
\hline Sacrum fracture & 7 & 3 \\
\hline Right ilium bone fracture & 8 & 6 \\
\hline Right iliopubic ramus fracture & 1 & 1 \\
\hline Right ischiopubic ramus fracture & 2 & 1 \\
\hline Left ilium bone fracture & 6 & 3 \\
\hline
\end{tabular}


Table 2. Cont.

\begin{tabular}{ccc}
\hline Anatomic Items & CT & Autopsy \\
\hline Left iliopubic ramus fracture & 2 & 1 \\
Left ischiopubic ramus fracture & 2 & 1 \\
Pelvic girdle fracture (sacrum + ilium + ischium) & 28 & 16 \\
Right humerus fracture & 12 & 12 \\
Right radius fracture & 1 & 0 \\
Right ulna fracture & 0 & 1 \\
Right hand fracture & 3 & 5 \\
Right upper limb & 16 & 18 \\
Left humerus fracture & 10 & 13 \\
Left radius fracture & 2 & 2 \\
Left ulna fracture & 3 & 4 \\
Left hand fracture & 6 & 10 \\
Left upper limb & 21 & 29 \\
Right femur fracture & 6 & 4 \\
Right tibia fracture & 1 & 1 \\
Right fibula fracture & 1 & 1 \\
Right foot fracture & 1 & 1 \\
Right lower limb & 9 & 7 \\
Left femur fracture & 2 & 2 \\
Left tibia fracture & 1 & 0 \\
Left fibula fracture & 1 & 0 \\
Left foot fracture & 0 & 0 \\
Left lower limb & 4 & 2 \\
Shot residue on skin & 1 & 6 \\
\hline
\end{tabular}

Figures 1-3 show correlations between CT scan data and autopsy photographs.

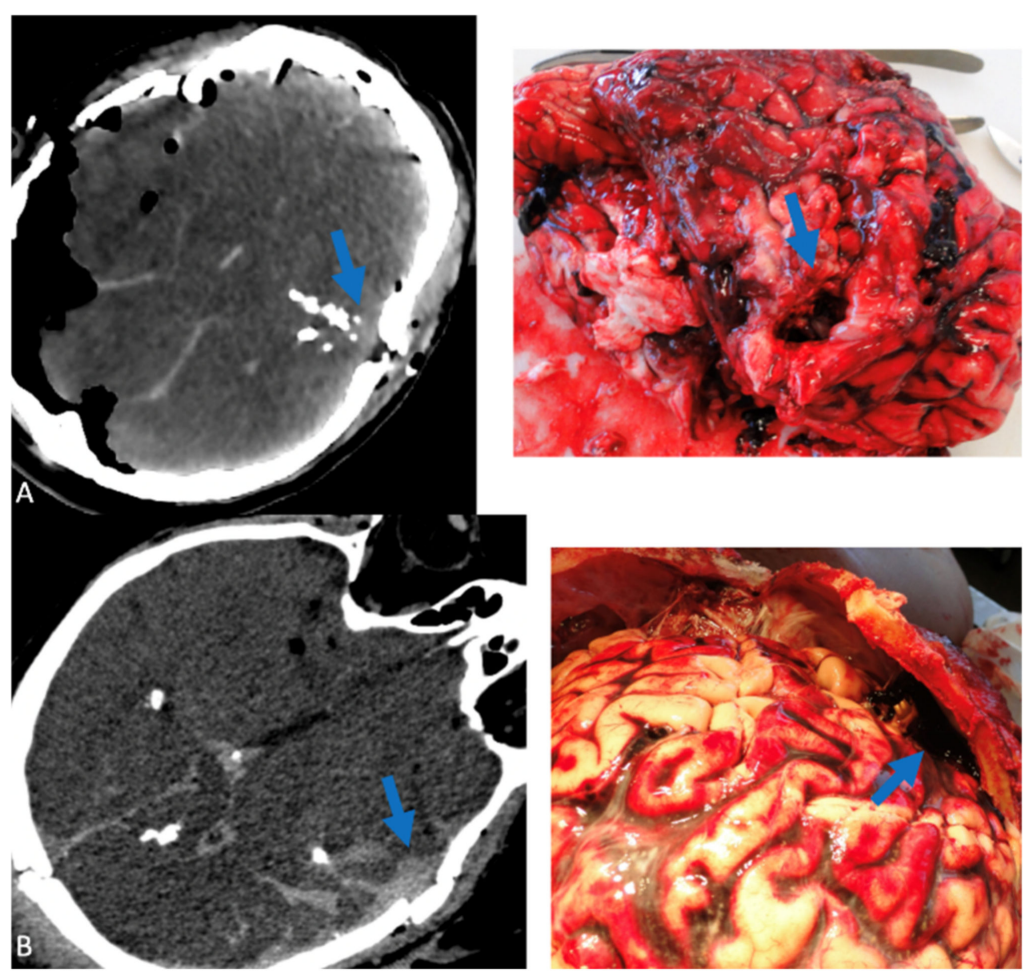

Figure 1. Correlations between CT scan and autopsy concerning cephalic lesions (arrows) (A) left temporal lobe lesion, (B) left subdural hematoma. 


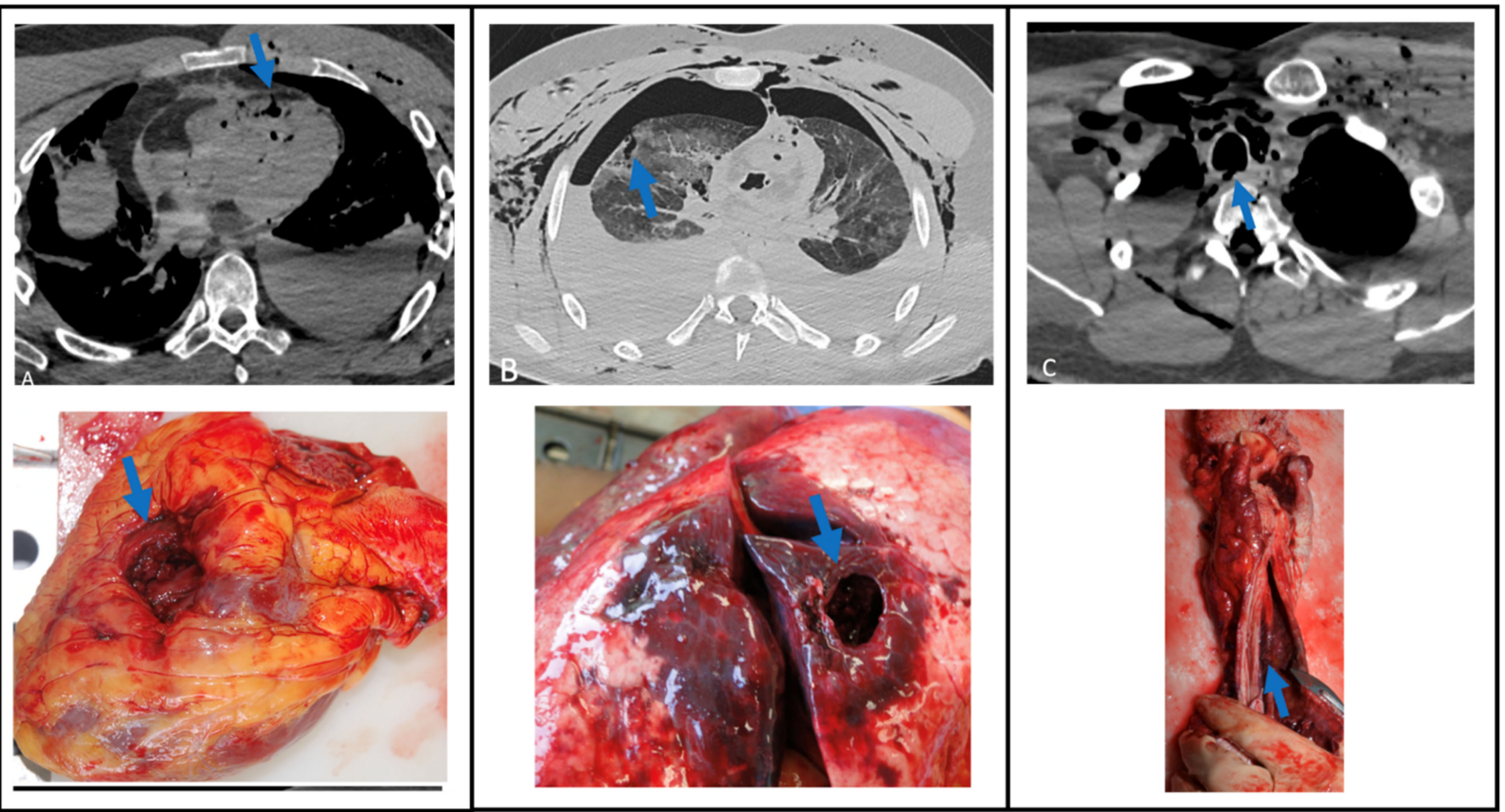

Figure 2. Correlations between CT scan and autopsy concerning thoracic lesions (arrows) (A) heart lesion, (B) right lung lesion, (C) lesion of the posterior wall of the trachea.

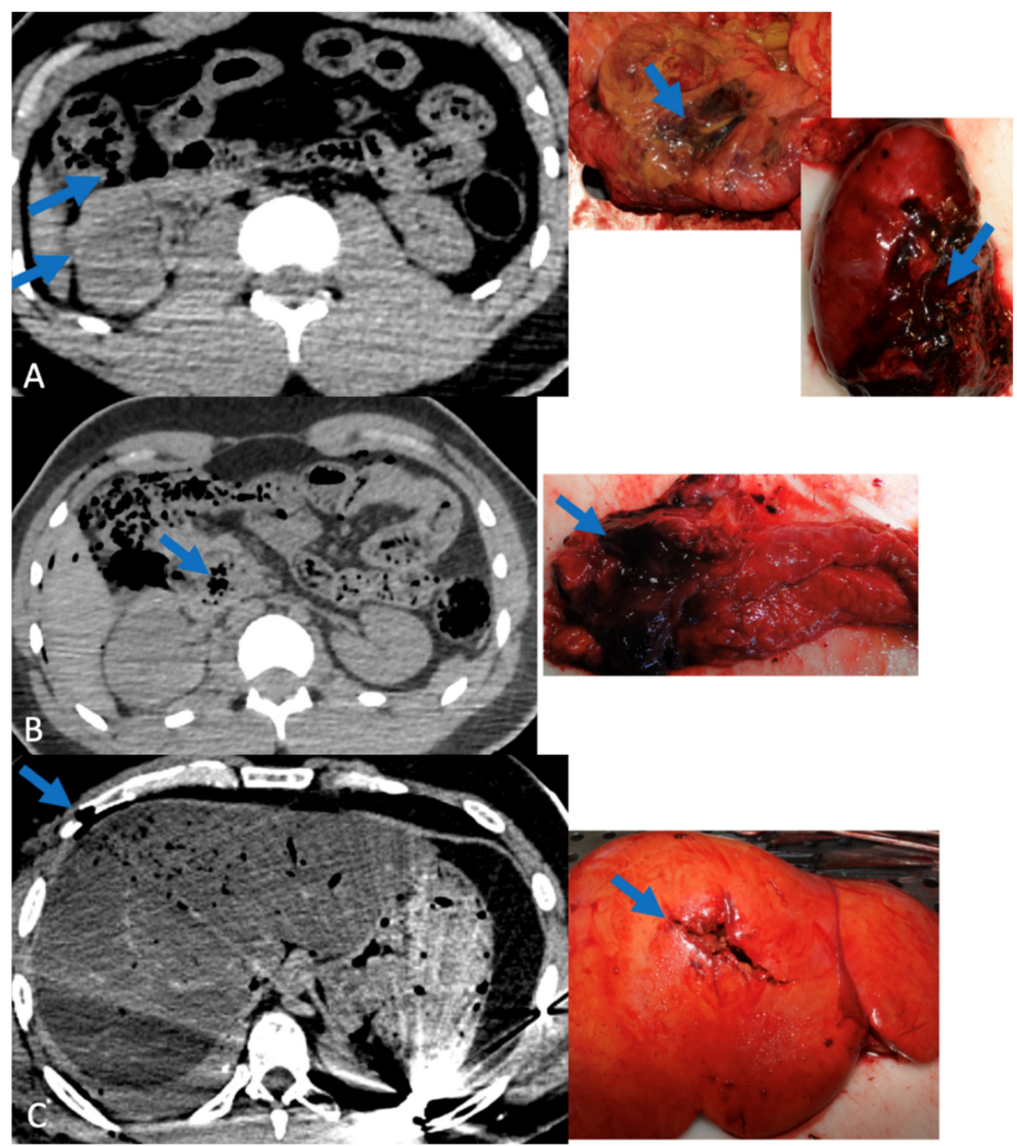

Figure 3. Correlations between CT scan and autopsy concerning abdominal lesions (arrows), (A) right colon and right kidney lesions, (B) lesion of the head of the pancreas, $(\mathbf{C})$ liver lesion. 


\section{Discussion}

We report the largest series [8-11] that evaluates the respective contributions, correlations, and discrepancies of unenhanced PMCT and autopsy in cases of firearm deaths.

PMCT and autopsy showed very good agreement overall, whether in the description of the location of projectiles or the number and direction of wounds, as in the literature [16-20].

Unlike a previous study [14], we found the two techniques were concordant in describing injuries of solid intra-abdominal organs, probably because the bullet path could be followed through the organs, which is not the case with non-penetrating trauma. This finding may be due in particular to the experience and training (more than 1200 cases in 10 years) of our radiological team. PMCT was efficient for the detection of bone fractures, in particular of deep bones such as the pelvic bones or the first cervical vertebrae, as reported [21]. These structures require deep dissection to be revealed at autopsy.

Injuries of the inferior vena cava were very few in number, which may have led to the lack of agreement. (Figure 4).

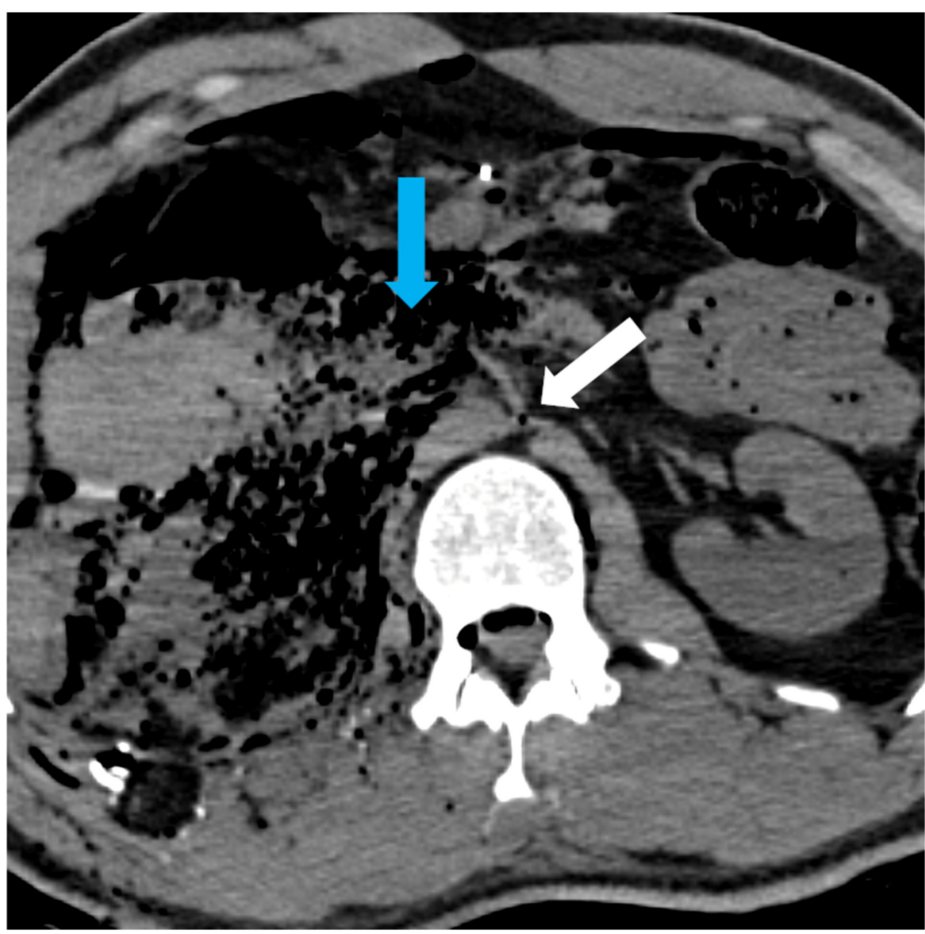

Figure 4. IVC not visible under hepatic, in emphysematous changes (blue arrow). Abdominal aorta collapsed with the birth of the Superior Mesenteric Artery (white arrow).

The discrepancy in detecting pneumothorax, where PMCT is reported to be informative [22-24], may be explained by the difficulty for forensic pathologists to ascertain the traumatic origin of pneumothorax after opening the chest cavity. The systematic lung retraction when the chest cavity is opened makes it difficult to correlate with a ballistic trajectory.

The discrepancy in detection and precise quantification of liquid effusions may be related to loss of liquid when the cavities are opened, to variable quantification of blood when it begins to clot, and to potential contamination between cavities when both hemothorax and hemoperitoneum are present.

The major discrepancies between PMCT and autopsy in the detection and quantification of gaseous and liquid effusions could suggest PMCT as the gold standard in such cases [25]. Evaluation of effusions (whether liquid or gaseous) on PMCT images is extremely precise, thanks to the digital post-processing tools available. Also, key images saved from the CT images can provide tangible evidence of the quantity of effusion. 
The limitations of PMCT were the position of the limbs outside the field of acquisition and the impossibility of reliably determining the caliber of the projectiles. Projectiles are almost always deformed on impact, whether by an intervening surface (car door, bone) or by the metallic artifacts inherent to volume acquisition and X-rays. Moreover, our analysis of the autopsy and ballistic reports showed differences between the calibers related to the complexity and variety of existing calibers. PMCT can detect small metal fragments [16], whereas autopsy requires time-consuming exploration to identify all the foreign bodies.

Some entry or exit wounds located on the victims' backs were difficult to analyze on PMCT because of postmortem deformation and compression of cutaneous and subcutaneous tissues, by the body's weight (scan performed in the supine position), and by the thickness of clothing.

Unlike CT scans, autopsy allowed the detection of gunshot residues during the description phase of the skin lesions.

One of the limitations was the exclusion of cases with more than 7 wound paths. Our experience showed that when injuries are too numerous, the body is extremely damaged, emphysematous bubbles are dispersed, the organs are fragmented, and it becomes difficult to identify individual trajectories precisely. The inclusion of these cases would have resulted in misleading statistical analysis.

Due to the large number of cases, we also determined that we could exclude bodies where charring and/or putrefaction were too advanced, in which bullet trajectories can be tricky to assess.

The literature shows that PMCT with the injection of contrast media, or postmortem CT angiography (PMCTA) [26-29], performs very well in the search for the cause of unexpected hospital deaths [30] or the detection of vascular injury [31]. Our study could potentially have detected a larger number of injuries if PMCT had been performed with contrast media. However, PMCTA techniques (costly and always time-consuming) are not currently available in most postmortem imaging centers. Thus, we considered it important to share the results obtained with the technique currently and most commonly used.

The demonstrative power of CT images, after analysis by an experienced radiologist, its potential and the issues at stake, could serve to build up a unique database. If PMCT were to be systematically performed in cases of firearm deaths and followed by the production of a standardized internationally validated report and 3D reconstructions, this could open the way to large-scale reflection on the issues of firearms and their prevention. Indeed, this standardized, validated report could allow harmonizing the practices on an international level by improving the performances of the PMCT and thus of the final autopsy report, which could use it as a complement of relevant information. The prosecution file could be supplemented by relevant images, notably by virtual reconstructions of crime scenes [32], supporting the conclusions of the autopsy report and the scientific police. Another advantage of CT is that it is more easily accepted in some religious communities than autopsy, while providing considerable information on the circumstances of death and enabling practices to become truly internationalized.

\section{Conclusions}

This study detailed the accordance of unenhanced PMCT and autopsy in analyzing ballistic injuries. PMCT agreed with the autopsy on the number and direction of surface wounds and pathways, as well as the description of injuries of the brain, heart, lungs, and solid intra-abdominal organs. In view of the major discrepancies observed in the detection and quantification of liquid and gaseous effusions, PMCT could be proposed where these are concerned. If carried out as an adjuvant to unenhanced PMCT, PMCTA could detect vascular and cardiac injuries that are less severe but are needed for exhaustive research of causes of death. Systematic PMCT after gunshot death could lead to international validation of a standardized report. The impact would not be restricted to an accurate description of injuries but would also serve to compile evidence for the prosecution, en- 
riching our understanding of the mechanisms of ballistic injury and promoting prevention and education $[33,34]$.

Author Contributions: Conceptualization, P.M. and G.G.; methodology, P.G., J.M., C.B. and G.G.; validation, L.T., M.-D.P. and G.G.; formal analysis, J.M.; investigation, P.G.; resources, J.M.; data curation, J.M.; writing — original draft preparation, P.G.; writing—review and editing, L.T., J.M., C.D., P.M. and G.G.; visualization, P.G.; supervision, G.G.; project administration, G.G.; funding acquisition, Not applicable. All authors have read and agreed to the published version of the manuscript.

Funding: This research received no external funding.

Institutional Review Board Statement: The study was conducted according to the guidelines of the Declaration of Helsinki. Ethical review and approval were waived due to the postmortem judicial setting of the work. Data were acquired within the framework of the legal investigation on behalf of the responsible legal authority.

Informed Consent Statement: Patient consent was waived due to the postmortem judicial setting of the work. Data were acquired within the framework of the legal investigation on behalf of the responsible legal authority.

Acknowledgments: The authors thank to all the radiology and mortuary technicians involved in this work.

Conflicts of Interest: The authors declare no conflict of interest.

\section{References}

1. Thali, M.J.; Yen, K.; Vock, P.; Ozdoba, C.; Kneubuehl, B.P.; Sonnenschein, M.; Dirnhofer, R. Image-guided virtual autopsy findings of gunshot victims performed with multi-slice computed tomography (MSCT) and magnetic resonance imaging (MRI) and subsequent correlation between radiology and autopsy findings. Forensic Sci. Int. 2003, 138, 8-16. [CrossRef]

2. Folio, L.R.; Fischer, T.V.; Shogan, P.J.; Frew, M.I.; Kang, P.S.; Bünger, R.; Provenzale, J.M. CT-based Ballistic Wound Path Identification and Trajectory Analysis in Anatomic Ballistic Phantoms. Radiology 2011, 258, 923-929. [CrossRef] [PubMed]

3. Thali, M.J.; Viner, M.D.; Brogdon, B.G. Brogdon's Forensic Radiology, 2nd ed.; CRC Press: Boca Raton, FL, USA, 2010.

4. Giorgetti, A.; Giraudo, C.; Viero, A.; Bisceglia, M.; Lupi, A.; Fais, P.; Quaia, E.; Montisci, M.; Cecchetto, G.; Viel, G. Radiological investigation of gunshot wounds: A systematic review of published evidence. Int. J. Leg. Med. 2019, 133, 1149-1158. [CrossRef] [PubMed]

5. Di Maio, V.J. Wounds from civilian and military centerfire rifles. Clin. Lab Med. 1998, 18, 189-201. [CrossRef]

6. Knight, B. How radiography aids forensic medicine. Radiography 1984, 50, 5-10.

7. Tuchtan, L.; Gorincour, G.; Kolopp, M.; Massiani, P.; Léonetti, G.; Piercecchi-Marti, M.-D.; Bartoli, C. Combined use of postmortem 3D computed tomography reconstructions and 3D-design software for postmortem ballistic analysis. Diagn. Interv. Imaging 2017, 98, 809-812. [CrossRef]

8. Kirchhoff, S.M.; Scaparra, E.F.; Grimm, J.; Scherr, M.; Graw, M.; Reiser, M.F.; Peschel, O. Postmortem computed tomography (PMCT) and autopsy in deadly gunshot wounds-A comparative study. Int. J. Leg. Med. 2015, 130, 819-826. [CrossRef]

9. Makhlouf, F.; Scolan, V.; Ferretti, G.; Stahl, C.; Paysant, F. Gunshot fatalities: Correlation between postmortem multi-slice computed tomography and autopsy findings: A 30-months retrospective study. Leg. Med. 2013, 15, 145-148. [CrossRef]

10. Andenmatten, M.; Thali, M.; Kneubuehl, B.; Oesterhelweg, L.; Ross, S.; Spendlove, D.; Bolliger, S. Gunshot injuries detected by postmortem multislice computed tomography (MSCT): A feasibility study. Leg. Med. 2008, 10, 287-292. [CrossRef]

11. Levy, A.D.; Abbott, R.M.; Mallak, C.T.; Getz, J.M.; Harcke, H.T.; Champion, H.R.; Pearse, L.A. Virtual Autopsy: Preliminary Experience in High-Velocity Gunshot Wound Victims. Radiology 2006, 240, 522-528. [CrossRef]

12. Lemieux, F.; Bricknell, S.; Prenzler, T. Mass shootings in Australia and the United States, 1981-2013. J. Criminol. Res. Policy Pract. 2015, 1, 131-142. [CrossRef]

13. Gorincour, G.; Tassy, S.; Bartoli, C. Why the United States Should Have Virtopsied Osama Bin Laden. Am. J. Roentgenol. 2012, 198, W323. [CrossRef]

14. Álvarez, A.C.; Mancini, J.; Tuchtan-Torrents, L.; Gach, P.; Bartoli, C.; Desfeux, J.; Piercecchi, M.; Gorincour, G. Diagnostic value of unenhanced postmortem computed tomography in the detection of traumatic abdominal injuries. Diagn. Interv. Imaging 2018, 99, 397-402. [CrossRef]

15. Koch, G.G.; Landis, J.R.; Freeman, J.L.; Freeman, D.H., Jr.; Lehnen, R.C. A general methodology for the analysis of experiments with repeated measurement of categorical data. Biometrics 1977, 33, 133-158. [CrossRef]

16. Colard, T.; Delannoy, Y.; Bresson, F.; Marechal, C.; Raul, J.; Hedouin, V. 3D-MSCT imaging of bullet trajectory in 3D crime scene reconstruction: Two case reports. Leg. Med. 2013, 15, 318-322. [CrossRef]

17. Delteil, C.; Gach, P.; Ben Nejma, N.; Capasso, F.; Perich, P.; Massiani, P.; Gorincour, G.; Piercecchi-Marti, M.-D.; Tuchtan, L. Tangential cranial ballistic impact: An illustration of the limitations of post-mortem CT scan? Leg. Med. 2018, 32, 61-65. [CrossRef] 
18. Garetier, M.; Deloire, L.; Dédouit, F.; Dumousset, E.; Saccardy, C.; Ben Salem, D. Postmortem computed tomography findings in suicide victims. Diagn. Interv. Imaging 2017, 98, 101-112. [CrossRef]

19. Puentes, K.; Taveira, F.; Madureira, A.J.; Santos, A.; Magalhães, T. Three-dimensional reconstitution of bullet trajectory in gunshot wounds: A case report. J. Forensic Leg. Med. 2009, 16, 407-410. [CrossRef]

20. Rutty, G.N.; Boyce, P.; Robinson, C.E.; Jeffery, A.J.; Morgan, B. The role of computed tomography in terminal ballistic analysis. Int. J. Legal Med. 2007, 122, 1-5. [CrossRef]

21. Graziani, G.; Tal, S.; Adelman, A.; Kugel, C.; Bdolah-Abram, T.; Krispin, A. Usefulness of unenhanced post mortem computed tomography-Findings in postmortem non-contrast computed tomography of the head, neck and spine compared to traditional medicolegal autopsy. J. Forensic Leg. Med. 2018, 55, 105-111. [CrossRef]

22. Hasegawa, I.; Heinemann, A.; Tzikas, A.; Vogel, H.; Püschel, K. Criminal gunshot wound and iatrogenic tension pneumothorax detected by postmortem computed tomography. Leg. Med. 2014, 16, 154-156. [CrossRef] [PubMed]

23. Ampanozi, G.; Schwendener, N.; Krauskopf, A.; Thali, M.J.; Bartsch, C. Incidental occult gunshot wound detected by postmortem computed tomography. Forensic Sci. Med. Pathol. 2012, 9, 68-72. [CrossRef] [PubMed]

24. Daghfous, A.; Bouzaïdi, K.; Abdelkefi, M.; Rebai, S.; Zoghlemi, A.; Mbarek, M.; Marhoul, L.R. Contribution of imaging in the initial management of ballistic trauma. Diagn. Interv. Imaging 2015, 96, 45-55. [CrossRef] [PubMed]

25. Laurent, P.-E.; Coulange, M.; Mancini, J.; Bartoli, C.; Desfeux, J.; Piercecchi-Marti, M.-D.; Gorincour, G. Postmortem CT Appearance of Gas Collections in Fatal Diving Accidents. Am. J. Roentgenol. 2014, 203, 468-475. [CrossRef]

26. Grabherr, S.; Heinemann, A.; Vogel, H.; Rutty, G.; Morgan, B.; Woźniak, K.; Dedouit, F.; Fischer, F.; Lochner, S.; Wittig, H.; et al. Postmortem CT Angiography Compared with Autopsy: A Forensic Multicenter Study. Radiology 2018, 288, 270-276. [CrossRef]

27. Rutty, G.N.; Morgan, B.; Robinson, C.; Raj, V.; Pakkal, M.; Amoroso, J.; Visser, T.; Saunders, S.; Biggs, M.; Hollingbury, F.; et al. Diagnostic accuracy of postmortem $\mathrm{CT}$ with targeted coronary angiography versus autopsy for coroner-requested postmortem investigations: A prospective, masked, comparison study. Lancet 2017, 390, 145-154. [CrossRef]

28. Van Rijn, R.R.; Leth, P.M. Targeted coronary postmortem CT angiography, straight to the heart. Lancet 2017, 390, 100-101. [CrossRef]

29. Ross, S.G.; Bolliger, S.A.; Ampanozi, G.; Oesterhelweg, L.; Thali, M.J.; Flach, P.M. Postmortem CT Angiography: Capabilities and Limitations in Traumatic and Natural Causes of Death. RadioGraphics 2014, 34, 830-846. [CrossRef]

30. Wichmann, D.; Heinemann, A.; Weinberg, C.; Vogel, H.; Hoepker, W.W.; Grabherr, S.; Pueschel, K.; Kluge, S. Virtual Autopsy With Multiphase Postmortem Computed Tomographic Angiography Versus Traditional Medical Autopsy to Investigate Unexpected Deaths of Hospitalized Patients. Ann. Intern. Med. 2014, 160, 534. [CrossRef]

31. Chevallier, C.; Doenz, F.; Vaucher, P.; Palmiere, C.; Dominguez, A.; Binaghi, S.; Mangin, P.; Grabherr, S. Postmortem computed tomography angiography vs. conventional autopsy: Advantages and inconveniences of each method. Int. J. Leg. Med. 2013, 127, 981-989. [CrossRef]

32. Ebert, L.C.; Nguyen, T.T.; Breitbeck, R.; Braun, M.; Thali, M.J.; Ross, S. The forensic holodeck: An immersive display for forensic crime scene reconstructions. Forensic Sci. Med. Pathol. 2014, 10, 623-626. [CrossRef]

33. Campion, E.W.; Morrissey, S.; Malina, D.; Sacks, C.A.; Drazen, J.M. After the Mass Shooting in Las Vegas-Finding Common Ground on Gun Control. N. Engl. J. Med. 2017, 377, 1679-1680. [CrossRef]

34. Maa, J.; Darzi, A. Firearm Injuries and Violence Prevention-The Potential Power of a Surgeon General's Report. N. Engl. J. Med. 2018, 379, 408-410. [CrossRef] 